\title{
Research and Practices as to Managing the Operation of the Experimental Teaching Center
}

\author{
Bo $\mathrm{Li}^{1}$, Qiong Yang ${ }^{2}$ \\ ${ }^{1}$ Quality Mnoitoring and Assessment Center, Changchun University of Science and Technology, \\ Changchun 130022, China \\ ${ }^{2}$ Personnel division, Changchun University of Science and Technology, Changchun 130022, China \\ alb@cust.edu.cn, byangq@cust.edu.cn
}

Keywords: experimental education, operation, management, research and practice

\begin{abstract}
A number of solutions are proposed to improve the management level of the Experimental Instruction Demonstration Center and the quality of experimental education as well after analyzing relevant issues exist in the operation management of such center on various levels.
\end{abstract}

\section{Introduction}

In 2005, the Ministry of Education started the construction and approval work in connection with national experimental instruction demonstration center for the purpose of further driving higher education institutions to reform in respect of experimental education, facilitating premium educational resources to be integrated and shared as well as refining student cultivation mechanism that primarily focuses upon practice abilities and creativeness, thus improving the quality of higher education. To respond, CUST accordingly initiated to select and build experimental instruction centers while considered its own situation of experimental education for university graduates. After constructed relevant experimental instruction demonstration centers including 4 on the national level, 7 provincial and 9 university, CUST took the corresponding measures to deepen the reform and innovation of experimental education for university graduates, strengthen the construction of quality experimental education resources, share constructive outcomes with other educational laboratories at the university, and continue to grope for, research upon and try out an experimental education management system which is intended to develop student competency related to execution and innovation.

\section{We change our mind and improve conditions through system construction}

\subsection{Concept \& idea issue}

Since being viewed as outstanding in respect of education for university graduates by the Ministry of Education, CUST has completely changed its attitude towards experiments which used to be regarded inferior to theories. As soon as relevant regulations and rules are made and formulated, more funds are put into the aspects such as laboratory environment and facility construction, equipment procurement and faculty cultivation, and the system of reward and punishment is clearly established and all the academic staffs are totally marshaled to participate in experimental education.

2.2 System issue

As for the experimental education that has long remained in a less important position, a number of problems are caused, for example, in comparison with comprehensive and creative experiments, the experiments designed for demonstration and verification dominate the experimental education synopsis, and it is also difficult for various departments to share resources with each other, and the repetitive construction is commonly seen and lots of experiment devices are not used. To solve those problems mentioned above, it is necessary to reform the talent cultivation procedures and system thoroughly. 
CUST has stipulated relevant regulatory files since 2007, for instance, Method to Implement the Construction of Experimental Instruction Demonstration Centers of Changchun University of Science and Technology, Ways to Construct a University Student Science Innovation Practice Base Employed by Changchun University of Science and Technology and Approach to Implement the National University Student Creative Experiment Program by Changchun University of Science and Technology. As per those files, the education laboratory of each school is integrated into experimental instruction centers which are controlled on the levels of both school and CUST and headed by directors. Through this way, normal operation of the experimental instruction demonstration center can be ensured and the work relation between such center and other departments of each school is well coordinately so as to set up a team of instructors that is rationally organized as regards age, educational degree, title and work division.

2.3Issue concerning basic conditions like hardware input

However, as the construction of laboratories is not planned in a scientific way, and lack of foresight and complete view, laboratories are constructed repetitively and loosely rather than tightly correlated to subject construction, and the experimental education resources are not totally available for sharing, which not only causes a great waste of experimental education funds but also limits the influence of the experimental instruction demonstration center.

For the purpose of significantly lifting the hardware conditions of education laboratory for university graduates and also laying a solid foundation for the development of each experimental instruction demonstration center, CUST has adopted various actions since 2005, including applied for foreign loans, cooperated with the central and provincial authorities, and solely dedicated funds appropriated by the superior financial departments to laboratory environment improvement and device \& instrument procurement.

2.4Issue concerning irrational composition of experimental instruction team

Only raising the status and remuneration of laboratory education and management personnel can they be fully mobilized and retained. Due to such reason, CUST often provides opportunities to them for training and further study so as to gradually sharpen their ability and comprehensive quality and perfect personnel composition as well.

To allow the experimental education personnel exchanging opinions with counterparts from other domestic universities and also learning experience from them, thus ultimately improving our education and management level, CUST has organized experience exchange conferences and training classes for directors of the experimental instruction center (University Student Science Innovation Practice Base) since 2007 when the Ministry of Education launched the project of instruction quality and reform for higher education institutions. In addition, CUST spends approximately 2 million almost each year on dispatching instructors (amounted to 30 in aggregate) to well-known foreign universities for study, thus getting ready for international education and keeping up with foreign advanced experimental instruction.

\section{To improve the construction level}

3.1Implement the education concept which treats experimental education and theoretical education equally allover the university by means of discussion about the work of experimental education. Such concept emphasizes to instill students with knowledge while assisting them to master certain skills and complete self-refinement, which exactly reflects the reform thoughts of experimental education that are to "Reinforce Basis, Concentrate upon Ability Development and Value highly Creativeness”.

3.2Look into the construction situation involving experimental instruction demonstration centers on various levels, and arrange conferences and workshops for instructors so as to first locate problems, and then form an investigation report that is in turn handed to the Office of University President for solution.

3.3Organize the schools of arts and science belonging to CUST to research and investigate into different problems that have already been categorized, and learn experience from other universities of 
advanced experimental education. Additionally, formulate relevant experimental education criteria and increase the proportion of experimental education as per the new version of cultivation proposal for university graduates, Certain Suggestions of the Ministry of Education on further Strengthening the Work of Cultivating Talents through Practice by Higher Education Institutions (no.[2012]1), and the characteristics of various majors and talent cultivation requirements as well, namely, to ensure that the humanistic and social science majors account for at least $15 \%$ of the total credits (academic hours) and the science majors $25 \%$.

3.4Gradually build an experiment \& practice platform while organizing the ideas in connection with construction of experimental instruction demonstration centers and perfecting such construction. Stick to the principle of Plan ahead, Construct Key Projects and Share Resources to obtain funds from various origins, improve the conditions of education via experiments and practices and finally form an experimental instruction platform that covers seven major subjects and 56 majors for university graduates of CUST. Moreover, several measures like bringing different resources together, opening to outside and sharing large instruments and encouraging to research and develop proprietary instruments etc. are taken to speed up the construction of such center.

3.5The experimental instruction demonstration centers are controlled on two levels, i.e. the corresponding school and CUST itself, and headed by directors. Such mechanism is able to integrate experimental education with laboratory management, manage manpower and properties in a central approach, universally deploy and share resources and improve the efficiency of management and resource utilization. Formulate relevant rules and regulations to make the operation of such center scientific, standardized and normalized, What's more important, those laboratories always remain open to students who need to carry out experiments.

\section{Concentrate upon graduates and locate shortcomings lying in the operation and management details of the experimental instruction center by means of analysis, and also work out appropriate solutions based upon actual facts and through brainstorming.}

4.1Regarding the key points in the course that are difficult to understand and comprehend, invite students to involve in researching, developing and fabricating related teaching tools and always think about the education methods, means and reform from the perspective of students to update the structure of knowledge and keep up with the times. In order to improve the efficiency and result of classroom education, it is required to periodically carry out the research and development of teaching tools by students, especially those closely related to the contents of education, ultimately helping students master the essential points of knowledge that are considered critical for technical innovation outside the classroom.

4.2To prevent classroom knowledge from dislocated with actual application, the experiment technicians and instructors for experimental education are required to spend at least 2 months each year in the enterprise that has made and entered into an agreement of mutual construction with CUST or other related firms on understanding the latest application method of professional knowledge in the frontline of production. Instructors with project and production experience are preferred to certain extent when applying for research subjects and university student innovation programs. Moreover, facts like the time and agenda of factory practice are also taken into account while implementing annual individual evaluation. CUST also encourages the qualified instructors to do a part-time job in the management of an enterprise and when back to the classroom, they are not only able to teach in a more vivid, concrete and relevant way but also pass the modern enterprise management concepts to students who are preliminarily to get prepared in advance in respect of mind and ability.

4.3Present the puzzles that enterprises encounter with in the process of production as a creative experiment item to students following simple analysis and breakdown, which causes constructive results for both students and enterprises, i.e. for the former, they have a feeling of fulfillment and for the latter, the actual technical obstacles are removed, the production cost lowered and the innovation level increased. To sum up, such production-and-education-combined method not only allows students to put what's been learnt into practice but also help enterprises to tackle with troubles in the 
way of smooth production and familiarize with the advanced technical concepts of university and student's creative thoughts.

4.4Establish an innovation interaction platform for both enterprise and CUST. Via such platform, enterprises are allowed to post relevant technical difficulties that they have run into in the process of production with information concerning objective to be obtained, deadline of completion as well as amount of financial support that can be provided. Each student project team has to compete for such bid and only the one offering the most feasible plan at the lowest cost and within the shortest completion time can be finally awarded the contract. The winning team subsequently reports to the person in charge of such project from the corresponding enterprise the actual progress of ongoing research. When the research is over, both parties, i.e. the enterprise and CUST, will conduct verification together to judge whether the anticipated requirements and effects are materialized or not. Such approach drives students to get involved in the process of production, scientific research and innovation, master theoretical knowledge, and acquaint themselves with the latest status of certain industry and put what's been taught into practical use. As for the enterprise, they find an economical way to solve the real problems of production in the shortest period of time.

4.5Set up a management office to exclusively handle the issue of sharing large instrument and device that costs more than 500,000 and also for the purpose of avoiding repeated purchase. Formulate relevant regulations to cope with the situation when more than one department applies for using such large device so as to eliminate unnecessary influence upon work resulted from device sharing.

\section{The experimental instruction center on various levels operates well and presents great outcomes.}

Following years of struggling, CUST has gradually lifted the level of experimental education and the quality of talent cultivation. From now on, it will construct as usual the experimental instruction demonstration center on various levels systematically and according to the corresponding plans, combine theoretical research with practice and learn advanced concepts involving experimental education from other domestic higher education institutions. While continuing to develop student's ability of practice and spirit of innovation and further advancing the experimental education reform and innovation, CUST will also perfect the operation management mechanism, optimize the faculty for experimental education, invent new education models and exert the demonstration effect of each experimental instruction demonstration center to a full extent, eventually bringing the level of experimental education to new heights.

\section{References}

[1]Li, X. H,. Construction of Practical Teaching Demonstration Centers in Local Universities. Research and Exploration in Laboratory, 32(5),119-123 (2013).

[2]Wang, S.. Research and practice on resources sharing mechanism of experimental teaching demonstration centers. Experimental Technology Management, 30(1),134-136 (2013).

[3]Zhang, J. H.. Construction and practice on experimental teaching quality guarantee system of “211Project” local universities. Experimental Technology Management, 30(4),147-150 (2013).

[4]Ji, D. F.. Deepening system reform to push forward the construction of national and provincial experimental demonstrat ion centers. Experimental Technology Management,27(2),97-103(2013).

[5]Feng, Q, H.. Reforming Experimental Teaching to Cultivate the Engineering Practice Ability of University Students. Research and Exploration in Laboratory, 32(2),130-132 (2013).

[6]Liang, J. G.. Construction of Experimental Teaching Center in the Process of University Transformation. Research and Exploration in Laboratory, 32(6),305-307 (2013). 
[7]Yu, J. C.. Exploration and practice on cultivating students' experimental ability depending on experimental teaching demonstration. Experimental Technology Management,30(3),117-129 (2013).

[8]Gao, L. M.. Construction of a Management Platform in an Experimental Teaching Demonstration Center. Research and Exploration in Laboratory,32(2),116-218 (2013).

[9]Xie, J. L.. Deepening the Reform, Making Innovations on Construction of Experimental Teaching Demonstration Center. Research and Exploration in Laboratory,32(2),123-135 (2013).

[10]Di, K.. Exploration and practice on carrying out quality engineering construction of experimental teaching. Experimental Technology Management,30(1),15-24. (2013) 